\title{
Penggunaan Arang Aktif Berbahan Dasar Limbah Biomassa Pada Proses Filtrasi Air Groundtank Ditinjau dari Uji TDS, Uji Kejernihan dan Uji Fe
}

\author{
Yeni Ristya Wardani ${ }^{(1, a) *}$, Mardhiyyatin Naqiyah ${ }^{(1, b)}$, Devy Nurmayanti ${ }^{(1, c)}$, \\ Abdul Aziz N.R ${ }^{(1, d)}$, Suparno ${ }^{(2)}$ \\ ${ }^{(1 a, 1 b, 1 c, 1 d)}$ Magister Pendidikan Fisika, Universitas Negeri Yogyakarta, Yogyakarta, Indonesia, 55281 \\ ${ }^{(2)}$ Fakultas MIPA Universitas Negeri Yogyakarta, Yogyakarta, Indonesia, 55281 \\ Email : ${ }^{(1 a *)}$ yennyristya@gmail.com , ${ }^{(2)}$ suparno_mipa@uny.ac.id,
}

Diterima (15 Juni 2020), Direvisi (26 Juni 2020)

\begin{abstract}
Natural resources on Earth consist of abiotics and biotics. Water, including biotic natural resources is one of the most important elements in supporting the survival of human life. One of water source which was widely used by resident around the Yogyakarta State University was the water of Institute of Development and Quality of Education Assurance (Lembaga Pengembang dan Penjamin Mutu Pendidikan) of Yogyakarta State University. This water resource was used to fulfill the needs of employees, the institute visitors, and traders around Karangmalang Culinary Park. However, the prior observation showed that the color of the water was prone to muddy and contains many sediments substances. This research was aimed to filter the water of that institute into pure water according to the physics parameter. This research was conducted by utilizing biomass waste in the form of teak, husk, and coconut fiber to be processed into active charcoal which later used to filter the water. Additional materials used in this research were sand and gravel. The result of water's total dissolve solid (TDS) has decreased by using the three active charcoal of biomass waste. Among those activated charcoal, the carbon which formed by teak showed the most significant result. Furthermore, in Fe content test, the most significant result of decreasing Fe content was showed by activated charcoal from husk base material. It can be concluded that the most effective activated charcoal material was formed by teak biomass waste which has a large pore structure.
\end{abstract}

Keywords: active charcoal, biomass waste, filtration.

\begin{abstract}
Abstrak. Sumber daya alam di Bumi terdiri dari abiotik dan biotik. Air termasuk sumber daya alam biotik merupakan salah satu elemen terpenting dalam menunjang keberlangsungan hidup manusia. Salah satu sumber air yang banyak dimanfaatkan oleh warga di sekitar kampus Universitas Negeri Yogyakarta (UNY) adalah air yang berasal dari Lembaga Pengembang dan Penjamin Mutu Pendidikan (LPPMP) UNY. Sumber air ini banyak dimanfaatkan untuk memenuhi kebutuhan karyawan, pengunjung LPPMP dan pedagang di sekitar Taman Kuliner Karangmalang. Namun dari hasil pengamatan yang diperoleh, warna air LPPMP ini cenderung keruh dan mengandung banyak endapan zat. Penelitian ini bertujuan untuk menyaring air groundtank LPPMP UNY menjadi air yang jernih sesuai parameter fisika. Penelitian ini dilakukan dengan cara memanfaatkan limbah biomassa berupa jati, sekam, dan serabut kelapa untuk diolah menjadi arang aktif yang nantinya digunakan untuk memfiltrasi air. Bahan tambahan berupa pasir dan kerikil pada lapisan. Hasil uji total zat padat terlarut (TDS) air hasil filtrasi mengalami penurunan pada ketiga arang aktif limbah biomassa. Sedangkan di antara ketiga arang aktif tersebut, arang aktif dari bahan jati yang paling menunjukkan hasil penjernihan paling signifikan. Selanjutnya pada uji kandungan Fe, hasil penurunan kadar Fe paling signifikan terlihat pada arang aktif dari bahan dasar sekam. Hal ini dapat disimpulkan bahwa bahan arang aktif yang paling efektif adalah limbah biomassa jati yang mempunyai struktur pori-pori yang besar.
\end{abstract}

Kata kunci: arang aktif, limbah biomassa, filtrasi 


\section{PENDAHULUAN}

Sumber daya alam abiotik dan biotik yang tersedia di Bumi yaitu logam, mineral, kayu, air, udara, dan tanah merupakan dasar bagi kehidupan manusia dan sosial-ekonomi kesejahteraan. Berdasarkan fakta, sumber daya alam memiliki fungsi langsung maupun tidak langsung bagi manusia [1]. Air merupakan salah satu elemen terpenting dalam menunjang keberlangsungan hidup manusia. Jumlah penduduk bumi yang semakin bertambah mengindikasikan bahwa kebutuhan air akan semakin meningkat. Tanpa air murni, tidak mungkin makhluk hidup dapat bertahan hidup di mana pun. Rasio air tawar di planet Bumi sangat buruk dan permintaan meningkat seiring waktu untuk populasi yang terus bertambah [2].

National Geographic pernah mencatat terdapat dari $70 \%$ air yang melingkupi seluruh bumi, hanya sekitar $2.5 \%$ yang merupakan air segar [3]. Selebihnya adalah air laut atau yang memiliki sifat seperti air laut. Itulah mengapa negeri kaya air sangat mungkin terancam krisis air bersih, termasuk Indonesia.

Berdasarkan peraturan Menteri Kesehatan Republik Indonesia No. 32 Tahun 2017 tentang standar baku mutu kesehatan lingkungan dan persyaratan kesehatan air terdapat beberapa parameter yang harus diperiksa, diantaranya tingkat kekeruhan dengan kadar maksimum 25 NTU, zat padat terlarut TDS (Total Dissolved Solid) dengan standar maksimum $1000 \mathrm{mg} / \mathrm{L}$, dan kandungan besi maksimal $1 \mathrm{mg} / \mathrm{L}$ [4].

Salah satu sumber air yang banyak dimanfaatkan oleh warga di sekitar kampus Universitas Negeri Yogyakarta (UNY) adalah air yang berasal dari Lembaga Pengembang dan Penjamin Mutu Pendidikan (LPPMP) UNY. Sumber air ini banyak dimanfaatkan untuk memenuhi kebutuhan karyawan dan pengunjung LPPMP. Selain itu, air ini juga sering digunakan oleh pedagang di sekitar Taman Kuliner Karangmalang dan keperluan rumah tangga lainnya. Namun dari hasil pengamatan yang diperoleh, warna air LPPMP ini cenderung keruh dan mengandung banyak endapan zat.

Penelitian sebelumnya mendapatkan hasil bahwa air LPPMP mengandung kadar Fe yang cukup tinggi yakni 2,67 mg/L[5]. Hal tersebut dapat memicu timbulnya beberapa gangguan kesehatan jika dikonsumsi dalam jangka waktu yang lama, baik secara langsung maupun tidak langsung.

Logam Fe merupakan logam essensial yang keberadaanya dalam jumlah tertentu sangat dibutuhkan oleh makhluk hidup, namun dalam jumlah berlebih dapat menimbulkan efek racun. Tingginya kandungan logam $\mathrm{Fe}$ akan berdampak terhadap kesehatan manusia diantaranya bisa menyebabkan keracunan (muntah), kerusakan usus, penuaan dini hingga kematian mendadak, radang sendi, cacat lahir, gusi berdarah, kanker, sirosis ginjal, sembelit, diabetes, pusing, hepatitia, hipertensi, insomnia [6]. Kadar besi $(\mathrm{Fe})>1$ $\mathrm{mg} / \mathrm{L}$ membahayakan kehidupan organisme termasuk manusia [7].

Total Dissolve Solid (TDS) yaitu ukuran zat terlarut organik maupun anorganik yang terdapat dalam larutan. Penyebab utama terjadinya TDS adalah bahan anorganik berupa ion-ion yang terdapat diperairan. Sebagai contoh air buangan sabun, deterjen, sulfaktan, dsb. Penentuan padatan tersuspensi sangat berguna dalam menganalisis perairan yang tercemar[8]. Analisis TDS sangat penting karena dapat menggambarkan kualitas air tanah, khususnya dalam memahami intrusi 
air laut lebih baik daripada analisis EC (Electrical Conductivity) [9].

Air yang mengandung TDS tinggi sangat tidak baik bagi kesehatan manusia. Mineral dalam air tidak hilang dengan cara direbus. Bila terlalu banyak mineral anorganik dalam tubuh dan tidak dikeluarkan maka seiring berjalanya waktu akan mengendap di tubuh. Maka hal tersebut dapat menyebabkan katarak, batu ginjal, pengerasan pembuluh darah, tekanan darah tinggi, dan stroke[10].

Salah satu upaya yang dapat dilakukan untuk menanggulangi hal tersebut adalah dengan memanfaatkan arang sebagai bahan baku pembuatan karbon aktif untuk melakukan filtrasi. Karbon aktif yang terbuat dari residu karbon atau arang dapat sebagai absorben yag efektif dan murah karena dibuat dari hasil gasifikasi biomassa kayu [11]. Salah satu penelitian telah memanfaatkan karbon aktif untuk melakukan penjernihan air menemukan bahwa efisiensi penyerapan kadar besi dengan menggunakan batok kelapa sebagai karbon aktif sebesar $(90,6+0,2) \%$ dan telah memenuhi syarat sebagai air minum[12].

Semakin lama permintaan akan arang aktif terus meningkat namun bahan utama seperti batu bara, kayu maupun tempurung kelapa semakin tidak tersedia. Hal tersebut memungkinkan untuk membuat arang aktif dari limbah biomassa seperti dari bahan jerami, batu zaitun, kulit kacang, ampas kopi, dan biji-bijian[13].

Sudut padang lain, Indonesia sebagai negara agrasis mampu menghasilkan produk pertanian dan perkebunan beserta dengan limbahnya dalam jumlah yang sangat besar setiap tahunnya. Setiap tahun, terdapat sekitar 160 miliar ton limbah dari areal pertanian dan 80 miliar ton dari areal perhutanan. Apabila tidak ditangani dengan baik, limbah pertanian dan perkebunan akan menjadi masalah dalam hal lingkungan hidup [14].
Salah satu Provinsi di Indonesia yaitu Provinsi Yogyakarta memiliki hutan seluas $18.715,0640 \mathrm{Ha}$ dengan rincian 71,66\% merupakan hutan produksi, $12,36 \%$ hutan lindung, dan 15,98\% hutan konservasi[15]. Data tersebut menunujukan bahwa potensi industri kayu di Yogyakarta cukup besar dan tentunya akan berbanding lurus dengan besarnya potensi limbah biomassa yang dihasilkan. Limbah yang dimaksud dapat berupa ranting yang jatuh dan limbah serbuk gergaji pada penebangan atau pemotongan kayu.

Selain itu, sektor pertanian, khususnya sawah, juga menyumbang limbah dalam jumlah yang besar. Salah satu limbah yang banyak dihasilkan adalah sekam dengan bobot sekitar 20-30 \% dari bobot awal gabah. Hal ini berpotensi menjadi masalah bila tidak dimanfaatkan dengan baik mengingat jumlah lahan sawah yang luas yakni 56.364 Ha [16]. Sedangkan pada sekor perkebunan di wilayah Yogyakarta, limbah biomassa terbesar terdapat pada perkebunan kelapa, dengan luas total 43.016,28 Ha. Limbah biomassa pada buah kelapa terdiri dari sabut dan tempurung kelapa yang memiliki massa dari buah kelapa utuh masing-masing 35\% dan 12\% [17]. Limbah biomassa memiliki potensi besar sebagai sumber energi terbarukan baik untuk negara maju maupun berkembang contohnya dapat dikemas dalam bentuk briket [18].

Secara umum, limbah biomassa banyak dimanfaatkan untuk diolah menjadi bahan bakar alternatif berupa briket. Lebih jauh lagi, sebagian kecil limbah yang dihasilkan digunakan sebagai pakan ternak atau dimanfaatkan sebagai kayu bakar. Selain itu, limbah biomassa ini dapat digunakan sebagai bahan dasar untuk membuat arang aktif yang dapat digunakan untuk beberapa tujuan, salah satunya sebagai bahan untuk filtrasi air.

Berdasarkan uraian tersebut, maka akan dilakukan penelitian mengenai pemanfaatan limbah biomassa berupa 
sekam, ranting jati, dan serabut kelapa sebagai bahan baku pembuatan arang aktif untuk melakukan filtrasi terhadap air LPPMP UNY.

\section{METODE PENELITIAN}

Penelitian ini bertujuan untuk menyaring air groundtank LPPMP UNY menjadi air yang jernih sesuai parameter fisika. Penelitian ini dilakukan dengan cara memanfaatkan limbah biomassa berupa jati, sekam padi, dan serabut kelapa. Ketiga bahan limbah biomassa diolah menjadi arang aktif yang nantinya digunakan untuk memfiltrasi air. Selain itu, penelitian ini juga menggunakan pasir silika dan kerikil sebagai bahan tambahan untuk proses filtrasi air. Adapun prosedur penelitian dilakukan melalui beberapa tahapan, yakni:

\section{Pembuatan Arang}

Penelitian diawali dengan tahap karbonisasi. Pada tahap ini, bahan-bahan yang ingin dijadikan arang terlebih dahulu dipotong kecil-kecil. Setelah itu, arang dan tempurung kelapa dimasukkan ke dalam kaleng (yang sebelumnya telah dikubur di dalam tanah) untuk dijadikan sebagai starter agar menghasilkan api atau bara yang cukup untuk membakar dan memanaskan bahan yang ingin dijadikan arang.

Bahan yang telah dipotong kecil-kecil kemudian dimasukkan ke dalam kaleng dan ditutup agar tidak ada udara yang masuk ke dalam kaleng dengan tujuan agar arang tidak berubah menjadi abu. Kaleng kembali dibuka setelah \pm 24 jam dan proses ini selesai ketika semua bahan sudah sepenuhnya berubah menjadi karbon. Prosedur yang sama berlaku untuk dua limbah biomassa lainnya. Selanjutnya karbon dihaluskan dan diayak menggunakan ayakan 100 mesh.

\section{Aktivasi Bahan}

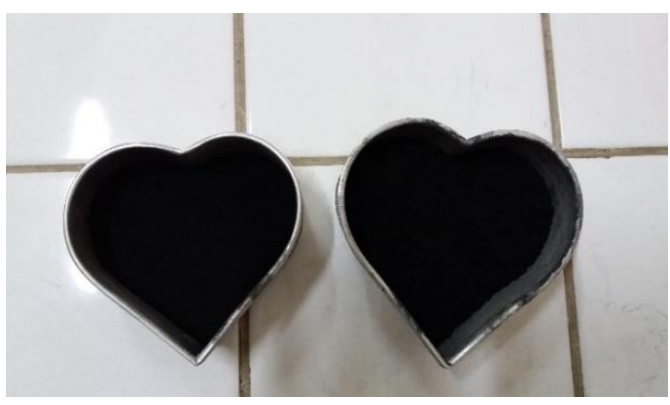

Gambar 1. Hasil Arang aktif limbah biomassa

Sebelum diaktivasi, semua bahan (arang, pasir, dan kerikil) terlebih dahulu dicuci menggunakan air RO sampai bersih. Bahan kemudian diaktivasi secara fisika dengan cara dipanaskan di dalam oven pada suhu $200^{\circ} \mathrm{C}$ selama 60 menit. Setelah dioven, hasil arang aktif menjadi sebagai berikut di Gambar 1.

\section{Proses Filtrasi}

Proses filtrasi merupakan proses pemisahan komponen padat atau koloid dengan cairan melalui cara melewatkannya menggunakan media berpori[19]. Sebelum air dari groudtank LPPMP difiltrasi, terlebih dahulu dibuat alat filtrasi dengan menggunakan botol transparan berukuran $100 \mathrm{ml}$. Botol ini kemudian diisi dengan bahan yang telah diaktivasi dengan urutan dari bawah ke atas adalah kerikil, pasir, dan karbon aktif. Bahan pelapis antar bahan menggunakan plastik yang telah dilubangi agar air dapat mengalir.

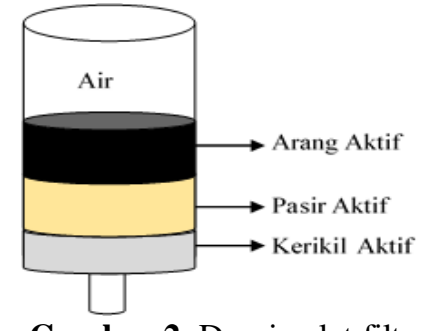

Gambar 2. Desain alat filtrasi 
Pasir dan kerikil dijadikan sebagai variabel kontrol dengan massa masingmasing 15,0 gram dan 20,0 gram. Massa arang dari limbah biomassa menjadi variabel manipulasi dengan masing-masng jenis divariasikan sebanyak 5,0 gram, 10,0 gram, dan 15,0 gram. Berdasarkan variasi dari setiap jenis arang aktif tersebut akhirnya diperoleh 9 sampel.

\section{HASIL DAN PEMBAHASAN}

\section{Uji TDS}

Total zat padat terlarut (TDS) merupakan salah satu indikator kelayakan air bersih. Sembilan sampel air yang telah disaring dengan variasi massa arang aktif diukur dengan menggunakan alat ukur TDS meter untuk mengetahui total zat padat terlarut. Pengukuran dilakukan dengan cara mencelupkan alat ukur ke dalam sampel air, dimana saat akan berganti mengukur air sampel lain bagian ujung alat harus dibersihkan. Pengukuran hasil uji TDS air mula-mula sebesar $163 \pm 0,5$ ppm. Berikut hasil pengukuran total zat padat terlarut dari kesembilan sampel disajikan dalam Tabel 1. Semakin besar massa arang aktif yang digunakan maka angka TDS mengalami penurunan. Hal itu disebabkan karena dengan bertambahnya massa arang aktif, maka pori-pori yang menyaring zat padat juga semakin besar.

Tabel 1. Hasil Pengukuran TDS

\begin{tabular}{cccc}
\hline No & $\begin{array}{c}\text { Jenis Limbah } \\
\text { Biomassa }\end{array}$ & $\begin{array}{c}\text { Massa } \\
\text { (gram) }\end{array}$ & $\begin{array}{c}\text { Hasil uji } \\
\text { TDS } \\
\text { (ppm) }\end{array}$ \\
\hline 1 & Sekam & 5 & $162 \pm 0,5$ \\
& & 10 & $153 \pm 0,5$ \\
\hline 2 & Jati & 5 & $143 \pm 0,5$ \\
\hline 3 & & 10 & $143 \pm 0,5$ \\
& Serabut & 5 & $141 \pm 0,5$ \\
\hline & kelapa & & $152 \pm 0,5$ \\
& & 10 & $146 \pm 0,5$ \\
& & 15 & $143 \pm 0,5$ \\
\hline
\end{tabular}

Dari tiga jenis limbah biomassa yang dijadikan sebagai bahan dasar, arang aktif yang terbuat dari limbah jati menyerap lebih banyak zat padat dibandingkan arang aktif yang terbuat dari sekam dan serabut kelapa. Hal ini disebabkan karena struktur jati lebih keras sehingga tidak mudah terkikis oleh air.

\section{Uji Kejernihan}

Kejernihan air dapat diukur melalui pengukuran intensitas cahaya. Pengukuran menggunakan rangkaian alat transmisi cahaya dengan prinsip melewatkan seberkas cahaya melalui wadah kaca yang sudah diisi dengan air kemudian cahaya yang melewati wadah kaca akan ditransmisikan ke luxmeter. Untuk mengetahui intensitas maksimal yang dapat ditangkap luxmeter, pengukuran awal dilakukan tanpa memasukkan air ke dalam wadah kaca. Setelah diketahui intensitasnya maksimalnya, kemudian mengukur air groundtank LPPMP UNY dan sampel air hasil filtrasi. Hasil uji kejernihan air mulamula $36 \pm 0,5$ lux. Hal yang perlu diperhatikan selama proses pengukuran berlangsung, diusahakan agar tidak ada cahaya luar yang masuk ke dalam rangkaian alat.

Berdasarkan Tabel 2, tingkat kejernihan air meningkat setelah proses filtrasi meggunakan ketiga jenis arang aktif. Di antara ketiga arang aktif tersebut, arang aktif dari bahan jati yang paling menunjukkan hasil penjernihan paling signifikan. Hasil inisejalan dengan hasil yang diperoleh pada uji TDS, dimana arang aktif yang terbuat dari jati mampu menyerap lebih banyak zat yang bisa membuat air menjadi keruh. 
Yeni Ristya Wardani, dkk: Penggunaan Arang Aktif Berbahan Dasar Limbah Biomassa Pada Proses

Filtrasi Air Groundtank Ditinjau dari Uji TDS, Uji Kejernihan dan Uji Fe

Tabel 2. Hasil Pengukuran Intensitas Cahaya

\begin{tabular}{cccc}
\hline No & $\begin{array}{c}\text { Jenis } \\
\text { Limbah } \\
\text { Biomassa }\end{array}$ & $\begin{array}{c}\text { Massa } \\
\text { (gram) }\end{array}$ & $\begin{array}{c}\text { Hasil uji } \\
\text { kejernihan } \\
\text { (lux) }\end{array}$ \\
\hline 1 & Sekam & 5 & $45 \pm 0,5$ \\
& & 10 & $52 \pm 0,5$ \\
& & 15 & $54 \pm 0,5$ \\
\hline 2 & Jati & 5 & $48 \pm 0,5$ \\
& & 10 & $49 \pm 0,5$ \\
& & 15 & $60 \pm 0,5$ \\
\hline 3 & Serabut & 5 & $38 \pm 0,5$ \\
& Kelapa & & \\
& & 10 & $45 \pm 0,5$ \\
& & 15 & $47 \pm 0,5$ \\
\hline
\end{tabular}

\section{Uji Kandungan Fe}

Pengukuran kadar besi (Fe) dilakukan dengan mengukur kadar besi awal pada air sebelum difiltrasi dan kadar besi akhir pada air hasil proses perlakuan dengan menggunakan alat Spektrofotometri UVVis. Hasil pengukuran kadar Fe air mulamula sebesar 0,2362 mg/L. Berikut ini hasil pengukuran total kadar logam besi $(\mathrm{Fe})$ setelah mengalami filtrasi menggunakan arang aktif limbah biomassa.

Tabel 3. Total kadar Logam Fe(Besi)

\begin{tabular}{cccc}
\hline No & $\begin{array}{c}\text { Jenis } \\
\text { Limbah } \\
\text { Biomassa }\end{array}$ & $\begin{array}{c}\text { Massa } \\
\text { (gram) }\end{array}$ & $\begin{array}{c}\text { Hasil uji } \\
\text { kadar Fe } \\
\text { (mg/L) }\end{array}$ \\
\hline 1 & Sekam & 5 & 0,0697 \\
& & 10 & 0,0516 \\
\hline 2 & Jati & 5 & 0,0937 \\
\hline 3 & & 10 & 0,2106 \\
& Serabut & 5 & 0,2449 \\
& Kelapa & & \\
& & 15 & 0,1599 \\
& & 15 & 0,2123 \\
\hline
\end{tabular}

Berdasarkan Tabel 3, kadar Fe berkurang setelah difiltrasi dengan arang aktif. Hasil yang paling signifikan terlihat pada arang aktif dari bahan dasar sekam. Meskipun begitu, kandungan logam pada air hasil filtrasi pada serabut kelapa 5 gram justru menunjukkan peningkatan. Hal ini mungkin disebabkan karena arang aktif telah mengalami kejenuhan saat proses filtrasi masih berlangsung sehingga terdapat kandungan logam yang ikut terlarut di dalam air hasil filtrasi.

\section{KESIMPULAN}

Berdasarkan penelitian dan pembahasan secara kualitatif dan kuantitatif dapat diperoleh kesimpulan bahwa ketiga bahan arang aktif limbah biomassa (sekam padi, jati, serabut kepala) efektif dalam memfiltrasi air yang keruh. Total zat padat terlarut berkurang secara signifikan untuk ketiga jenis arang aktif terutama arang aktif jati. Tingkat kekeruhan berkurang lebih baik jika menggunakan bahan arang aktif jati dan kandungan $\mathrm{Fe}$ berkurang signifikan jika menggunakan sekam. Hal ini dapat disimpulkan bahwa bahan dasar arang aktif dari limbah biomassa yang paling efektif adalah terbuat dari jati yang mempunyai pori-pori yang besar. Berdasarkan syarat syarat Permenkes untuk air bersih, variabelvariabel hasil akhir penyaringan yang diukur sudah memenuhi syarat tersebut.

\section{DAFTAR PUSTAKA}

[1] E. Crenna, S. Sozzo, and S. Sala, "Natural biotic resources in LCA: Towards an impact assessment model for sustainable supply chain management," J. Clean. Prod., 2017.

[2] S. Reza et al., "Preparation of activated carbon from biomass and its , applications in water and gas 
purification, a review," Arab J. Basic Appl. Sci., vol. 27, no. 1, pp. 208-238, 2020.

[3] F. Sido, "Sido, F. (2015). Google. Retrieved from Kompsiana.com:https://www.kompa siana.com/afsee/indonesia-bumiadalahair_55100a77813311ae36bc60a2,"

Kompasiana, 2015. [Online]. Available:

kompsiana.com:https://www.kompas iana.com/afsee/indonesia-bumiadalahair_55100a77813311ae36bc60a2.

[4] Kementrian Kesehatan Republik Indonesia, Peraturan Menteri Kesehatan Republik Indonesia No.32 Tahun 2017. Jakarta: Menteri Kesehatan Republik Indonesia., 2017.

[5] T. Widiastuti and S. Suparno, "Pemanfaatan Karbon Aktif Bambu, Pasi Aktif Pantai Indrayanti, dan kerikil Aktif Kali Krasak Sebagai Absorbent Pada Proses Penjernihan Air LPPMP UNY Untuk Air Minum," J. Fis., vol. 5, no. 2, pp. 123-136, 2016.

[6] A. Parulian, "Monitoring dan Analisis Kadar Aluminium (Al) dan Besi $(\mathrm{Fe})$ Pada Pengolahan Air Minum PDAM Tirtanadi Sunggal," Universitas Sumatera Utara (USU), 2009.

[7] M. James W, Inorganic Contaminant of Surface Water. New York: Springer Verlag, 1991.

[8] F. Srikandi, Mikrobiologi Pangan 1. Jakarta: Gramedia Pustaka Utama, 1992.

[9] A. F. Rusydi, "Correlation between conductivity and total dissolved solid in various type of water: A review," IOP Conf. Ser. Earth Environ. Sci., vol. 118, 2018.

[10] W. Nugroho and S. Purwoto, "Removal Klorida, TDS dan Besi pada Air Payau Melalui Penukar Ion dan Filtrasi Campuran Zeolit Aktif dengan Karbon Aktif," J. Tek. Waktu, vol. 11, no. 01, pp. 47-59, 2013.

[11] T. Maneerung, J. Liew, Y. Dai, S. Kawi, C. Chong, and C. Wang, "Activated carbon derived from carbon residue from biomass gasification and its application for dye adsorption: Kinetics, isotherms and thermodynamic studies," Bioresour. Technol., vol. 200, pp. 350-359, 2016.

[12] F. S. Primawati and S. Suparno, "Sistem Penjernihan Air Groundtank LPPMP UNY Sebagai Air Minum Dengan Memanfaatkan Karbon Aktif Batok Kelapa, pasir Aktif Pantai Indrayanti, dan Kerikil Aktif Kali Krasak,"J. Fis., vol. 5, no. 3, pp. 169178, 2016.

[13] E. Schröder, K. Thomauske, B. Oechsler, and S. Herberger, Activated Carbofrom Waste Biomass. Biomass and Bioenergy Production, 2011.

[14] Y. Yustinah and H. Hartini, "Adsorbsi Minyak Goreng Bekas Menggunakan Arang Aktif dari Sabut Kelapa," Pros. Semin. Nas. Tek. Kim. “Kejuangan” Pengemb. Teknol. Kim. untuk Pengolah. Sumber Daya Alam Indones., 2011.

[15] Badan Pusat Statistik Yogyakarta, Statistik Lingkungan Hidup D.I Yogyakarta. Yogyakarta: Badan Pusat Statistik Provinsi D.I Yogyakarta., 2012. 
Yeni Ristya Wardani, dkk: Penggunaan Arang Aktif Berbahan Dasar Limbah Biomassa Pada Proses Filtrasi Air Groundtank Ditinjau dari Uji TDS, Uji Kejernihan dan Uji Fe

[16] Y.Z. Kurdiawan, M. Erlangga, and S. R. Juliastuti, "Pemanfaatan Limbah Sekam Padi Menjadi Briket Sebagai Sumber Energi Alternatif dengan Proses Karbonisasi dan NonKarbonisasi," J. Tek. POMITS, vol. 2, no. $1,2013$.

[17] D. Pertiwi and W. Herumurti, "Studi Pemanfaatan Sabut Kelapa Sebagai Karbon Aktif Untuk Menurunkan Konsentrasi Fenol," Insitut Teknologi Sepuluh Nopember Surabaya, 2009.
[18] K. B. Deepak and N. A. Jnanesh, "Experimental Analysis of Physical and Fuel Characteristics of Areca Leaves Briquette," Int. J. Sci. Res., vol. 4, no. 1, 2015.

[19] R. Quddus, “Teknik Pengolahan Air Bersih Dengan Sistem Saringan Pasir Lambat (Downflow) Yang Bersumber Dari Sungai Musi," J. Tek. Sipil dan Lingkung., vol. 2, no. 4, pp. 669-675, 2014. 